\title{
Prevalence of Acute Compartment Syndrome of Limbs: A Retrospective Study
}

Sen SK1, Debnath S2

DOI: https:// doi.org/ 10.3329/ jafmc.v15i2.50835

\begin{abstract}
Introduction: Acute compartment syndrome (ACS) is a serious and well known complication of limb trauma. This condition is an orthopaedic emergency and is associated with significant morbidity if not diagnosed promptly and treated effectively.
\end{abstract}

Materials and Methods: This is a retrospective cross sectional study on the scope of compartment syndrome among patients with limbs traumas those were treated between April 2015 and November 2018 in a United Nations level-II Hospital at KagaBandoro in Central African Republic leaded by Bangladesh Medical Contingent. The medical records as well as data from the orthopaedic registrars of patients with limb injuries were studied. Limb injuries considered for in-hospital treatments with or without other associated system injuries were included while patients with any form of arterial diseases or claudication were excluded.

Results: A total of 320 patients met the inclusion criteria among them only $2.81 \%$ had ACS and male young adults were mostly affected. Commonest underlying pathology was tibia fracture $44.4 \%$, followed by due to tight traditional bone setters' splints $22.2 \%$ and $11.1 \%$ patients from burns eschar.

Conclusion: ACS of limb is not very common. Early clinical diagnosis in the absence of pressure monitoring equipment and emergency fasciotomies are recommended to salvage the limbs.

Key-words: Acute compartment syndrome, Fasciotomy, Orthopaedic emergency.

\section{Introduction}

Acute compartment syndrome (ACS) of the limbs is an orthopaedic emergency characterized by raised pressure within the closed osseofascial compartment above the limit that permits normal function of the muscles, nerves, and blood vessels within the compartment. Sustained elevation of tissue pressure reduces capillary perfusion below a level necessary for tissue viability, and irreversible muscle and nerve damage may occur within hours. Causes include trauma, revascularization procedures, burns and extreme exercise ${ }^{1}$. Compartment syndrome could arise in a limb due to three distinct pathological processes. First, the decrease in compartment volume from external compressive factors that compromise the blood flow and decrease the relative distensibility of the compartment such as cast and traditional bonesetters' splint. Second, the increase in the content of the compartment without a corresponding increase in space such as the accumulation of hematoma and inflammatory exudates within a tight osseofascial compartment causing decreased perfusion. Third, the reperfusion syndrome with the release of inflammatory mediators and accumulation of post ischemic edema that compromise further blood flow following delayed tourniquet removal. Sometimes, more than one pathological process may be involved in the development of ACS in a limb. This is recognized early by severe pain that is not in synchronization with the degree of injury and pain that is refractory to analgesics. Furthermore, a passive dorsiflexion of the toes will cause excruciating pain in the calf. These are the early features of ACS necessary for clinical diagnosis. The compartment syndrome is not so common, but clinicians should be familiar with its presentations, recognize it early and emergency treatment to avoid complications ${ }^{2,3}$. It has been noted that the most important cause of poor outcome from ACS is delay in diagnosis 4,5 . Unfortunately, in our environment, there are often delays in seeking contemporary orthopedic consults as many patients would patronize the traditional bone setters first and because of this, many cases of ACS present late as gangreneor at the stage when fasciotomy cannot prevent the late complication like Volkmann's ischemic contracture ${ }^{4-6}$.

Although the clinical features can be vague and nonspecific, the initial suspicion of a diagnosis is largely a clinical one. Clinical diagnosis is aided by some classic features including pain, pallor, pulselessness, paraesthesia, pressure, poikilothermia and paralysis. ACS is a dynamic process with incremental damage if it remains undiagnosed. Therefore, it may be beneficial for one experienced assessor to serially examine the patient so the evolution of the condition is noted rather than at one point in time? A delayed diagnosis of ACS and late fasciotomy could have catastrophic consequences and not only can it lead to loss of limb function or irreversible muscle damage, but also there may be the systemic manifestations of acidosis, hyperkalemia, myoglobinuria, shock, sepsis, and eventual renal failure that may lead to death8,9. Compartment pressure measurements and monitoring only become absolutely necessary when there is a suspicion, but the clinical features are equivocal ${ }^{3}$. However, compartment pressure varies in individuals and in a person from time to time, depending on the diastolic blood pressure ${ }^{3,10}$. The differential pressure between the compartmental and the diastolic pressures becomes critical if this delta $P$ is $<30 \mathrm{~mm} \mathrm{Hg}^{3}$ and this is an indication for fasciotomy. There is a paucity of reports from our environment and despite numerous studies on the etiology, methods and techniques of compartment pressure measurement, pathophysiology and management of compartment syndrome $3,5,10,11$.

\section{Materials and Methods}

This retrospective cross sectional study was carried out in a United Nations level-II hospital of Bangladesh Medical Contingent, located at Kaga-Bandoro in Central African Republic between April 2015 
and November 2018. The patients who had significant injuries that needed admission were included in the study. These were the patients with limb fractures with or without other associated injuries, those with burns involving the limb, and those with splints around their limbs. The patients with underlying vascular compromise such as peripheral vascular disease or claudication were excluded from the study.

The diagnosis of compartment syndrome was made by clinical methods only. All of these patients were local Central African treated as a part of our Civil-Military Cooperation activities. Their involved limbs were swollen and tense. The investigations included full blood count, serum electrolytes, $C$ reactive protein, urea, and creatinine before and after fasciotomies. Pulse oximetry SpO 2 was used for monitoring. All of the patients had emergency fasciotomies under general anesthesia and subsequently definitive treatment was given. The patients' folders within the study period were retrieved from the medical records. Data was also obtained from the operation registrars. The data analyzed included the age, sex, diagnosis, etiology, the part of the limb affected, the treatments carried out, complications, and the duration of hospital stay. Analysis was done with the Statistical Package for Social Sciences by International Business Machine (IBM-SPSS) version 20. Statistical significance was considered when $p$ value was $<0.05$. This study was approved by the Ethical Committee of the center having satisfied all issues about patients' confidentiality and the best practice methods concerning human research.

\section{Results}

The total number of patients with limb injuries treated within the period under review was 320 . There was statistically significant $(p$ $<0.05$ ) male predominance among all trauma patients, male to female ratio was 5.1:1. In this study, common fractures of trauma patients were closed fracture radius and ulna (14.7\%) followed by close fracture tibia (14.1\%) (Table-I). Total number of patients with compartment syndrome resulting from their injuries was $9(2.82 \%)$ with male-female ratio $3.5: 1, \quad(p<0.05)$. About $44.4 \%$ of compartment syndrome patients were in age group of 20-29 years and $22.2 \%$ in of $30-39$ years age group. The mean age of trauma patients was $31.47 \pm 11.59$ years (Table-II). In $44.4 \%$ cases etiology was road traffic accidents and in $22.2 \%$ cases fracture treated by bone setters' splint. Fracture tibia was $44.4 \%$, majority of which were close fracture (33.3\%). Only $11.1 \%$ patients had open fracture (Table-III). Open reduction and internal fixation (ORIF) with split thickness skin grafting (STSG) was done in one session in $44.44 \%$ cases after fasciotomy (Table-IV). In this study, no complication developed in $77.8 \%$ cases. Pyogenic osteomyelitis developed in $11 \%$ cases (Figure-1). Clinical outcome was evaluated at 6 months of surgery with pain score by Visual Analogue Scale and observing for other complications need further intervention. Satisfactory outcome means individual might return to previous job with no pain or complication and unsatisfactory outcome means individual could not return to previous job due to pain or other complications. Satisfactory result was obtained in $77.8 \%$ cases (Figure-2).
Table-I: Distribution of trauma patients according to initial injury and $\operatorname{sex}(n=320)$

\begin{tabular}{|l|c|c|c|}
\hline \multicolumn{1}{|c|}{ Diagnosis } & $\begin{array}{c}\text { Total } \\
\mathrm{n}(\%)\end{array}$ & $\begin{array}{c}\text { Male } \\
\mathrm{n}(\%)\end{array}$ & $\begin{array}{c}\text { Female } \\
\mathrm{n}(\%)\end{array}$ \\
\hline Closed fracture Tibia & $45(14.1)$ & $39(12.2)$ & $6(1.9)$ \\
\hline Open fracture Tibia & $28(8.7)$ & $22(6.8)$ & $6(1.9)$ \\
\hline Closed fracture Femur & $23(7.2)$ & $19(5.9)$ & $4(1.3)$ \\
\hline Open fracture Femur & $9(2.8)$ & $8(2.5)$ & $1(0.3)$ \\
\hline $\begin{array}{l}\text { Closed fracture shaft of } \\
\text { Humerus }\end{array}$ & $17(5.4)$ & $12(3.8)$ & $5(1.6)$ \\
\hline $\begin{array}{l}\text { Supracondylar fracture of } \\
\text { Humerus }\end{array}$ & $15(4.7)$ & $13(4.1)$ & $2(0.6)$ \\
\hline Closed fracture Radius \&Ulna & $47(14.7)$ & $36(11.3)$ & $11(3.4)$ \\
\hline Hand injuries & $34(10.6)$ & $31(9.7)$ & $3(0.9)$ \\
\hline Closed fracture Patella & $7(2.2)$ & $7(2.2)$ & 0 \\
\hline Pelvic Fracture & $6(1.9)$ & $5(1.6)$ & $1(0.3)$ \\
\hline Foot injuries & $39(12.2)$ & $34(10.6)$ & $5(1.6)$ \\
\hline Blunt trauma Limbs & $25(7.8)$ & $21(6.6)$ & $4(1.2)$ \\
\hline Burn of Limbs & $5(1.5)$ & $2(0.6)$ & $3(0.9)$ \\
\hline Lacerated injury of Limbs & $20(6.2)$ & $19(5.9)$ & $1(0.3)$ \\
\hline Total & $320(100)$ & $268(83.8)$ & $52(16.2)$ \\
\hline
\end{tabular}

Table-II: Distribution of trauma patients and ACS with age and sex

\begin{tabular}{|l|l|c|c|c|}
\hline Age(Years) & $\begin{array}{l}\text { Trauma } \\
\text { patients } \\
(n=320)\end{array}$ & \multicolumn{3}{|c|}{$\begin{array}{l}\text { ACS } \\
(n=9)\end{array}$} \\
\hline & Total (\%) & Male & Female & Total \\
\hline$<10$ & $6(1.9)$ & - & 1 & 1 \\
\hline $10-19$ & $23(7.3)$ & - & - & 0 \\
\hline $20-29$ & $129(40.1)$ & 3 & 1 & 4 \\
\hline $30-39$ & $99(30.8)$ & 2 & - & 2 \\
\hline $40-49$ & $40(12.6)$ & 1 & - & 1 \\
\hline $50-59$ & $13(4.2)$ & 1 & - & 1 \\
\hline$\geq 60$ & $10(3.1)$ & - & - & - \\
\hline Total & $320(100)$ & $7(2.19)$ & $2(0.63)$ & $9(2.81)$ \\
\hline Mean $\pm S D=31.47 \pm 11.59$ & \multicolumn{2}{|c|}{$M: F=3.5: 1, p<0.05$} \\
\hline
\end{tabular}

Table-III: Distribution of ACS by trauma / injury $(n=9)$

\begin{tabular}{|l|l|l|}
\hline $\begin{array}{l}\text { Cause of } \\
\text { trauma }\end{array}$ & \multicolumn{1}{|c|}{ Associated injury } & $\begin{array}{l}\text { Total } \\
(\%)\end{array}$ \\
\hline $\begin{array}{l}\text { Road traffic } \\
\text { accidents }\end{array}$ & $\begin{array}{l}\text { Closed Fracture Tibia(3)+ Closed } \\
\text { fracture femur(1) }\end{array}$ & $4(44.4)$ \\
\hline Gunshot injury & Open fracture Tibia & $1(11.1)$ \\
\hline Burn & Burn eschar & $1(11.1)$ \\
\hline $\begin{array}{l}\text { Bone setters' } \\
\text { splint }\end{array}$ & Supracondylar fracture Humerus & $2(22.2)$ \\
\hline $\begin{array}{l}\text { Physical } \\
\text { Assault }\end{array}$ & Blunt trauma leg & $1(11.1)$ \\
\hline Total (\%) & & $9(100)$ \\
\hline
\end{tabular}


Table-IV: Distribution of ACS by treatment $(n=9)$

\begin{tabular}{|l|l|c|c|}
\hline \multicolumn{1}{|c|}{$\begin{array}{c}\text { Associated } \\
\text { injury }\end{array}$} & \multicolumn{1}{|c|}{$\begin{array}{c}\text { Offered } \\
\text { treatment }\end{array}$} & Frequency & $\begin{array}{c}\text { Percentag } \\
\text { e }\end{array}$ \\
\hline $\begin{array}{l}\text { Closed Fracture } \\
\text { Femur }\end{array}$ & $\begin{array}{l}\text { Fasciotomy, } \\
\text { ORIF, STSG }\end{array}$ & 1 & 11.1 \\
\hline $\begin{array}{l}\text { Closed Fracture } \\
\text { Tibia }\end{array}$ & $\begin{array}{l}\text { Fasciotomy, } \\
\text { ORIF, STSG }\end{array}$ & 3 & 33.3 \\
\hline $\begin{array}{l}\text { Open fracture } \\
\text { Tibia }\end{array}$ & $\begin{array}{l}\text { Fasciotomy, Ex- } \\
\text { Fix, STSG }\end{array}$ & 1 & 11.1 \\
\hline $\begin{array}{l}\text { Blunt trauma } \\
\text { leg }\end{array}$ & $\begin{array}{l}\text { Fasciotomy, } \\
\text { splint }\end{array}$ & 1 & 11.1 \\
\hline $\begin{array}{l}\text { Supracondylar } \\
\text { fracture } \\
\text { Humerus }\end{array}$ & $\begin{array}{l}\text { Fasciotomy, } \\
\text { percutaneous } \\
\text { pinning, splint }\end{array}$ & 2 & 22.2 \\
\hline Burn eschar & $\begin{array}{l}\text { Escharotomy, } \\
\text { splint }\end{array}$ & 1 & 11.1 \\
\hline Total & & 9 & 100 \\
\hline
\end{tabular}

Note: ORIF= open reduction \& internal fixation, STSG = split thickness skin graft

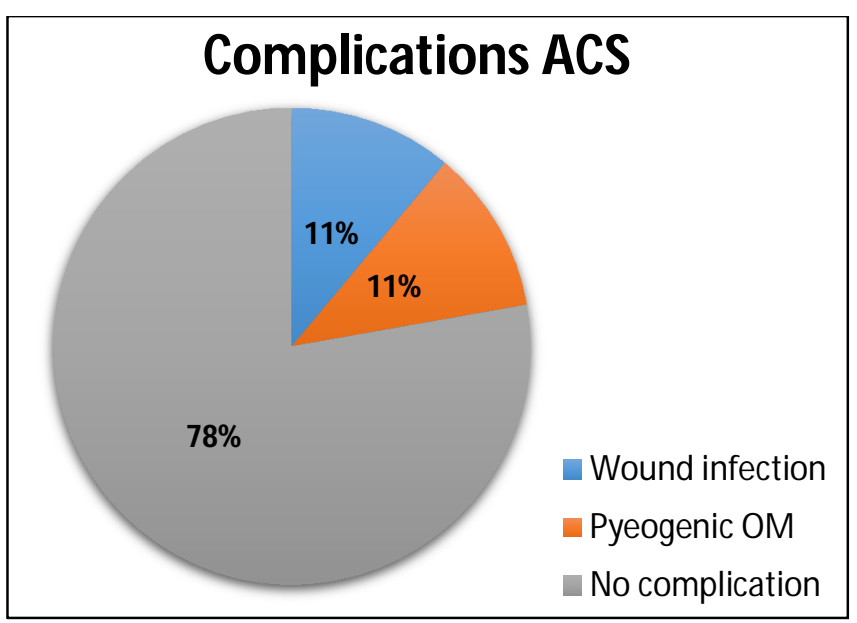

Figure-1: Distribution of ACS by complications $(n=9)$

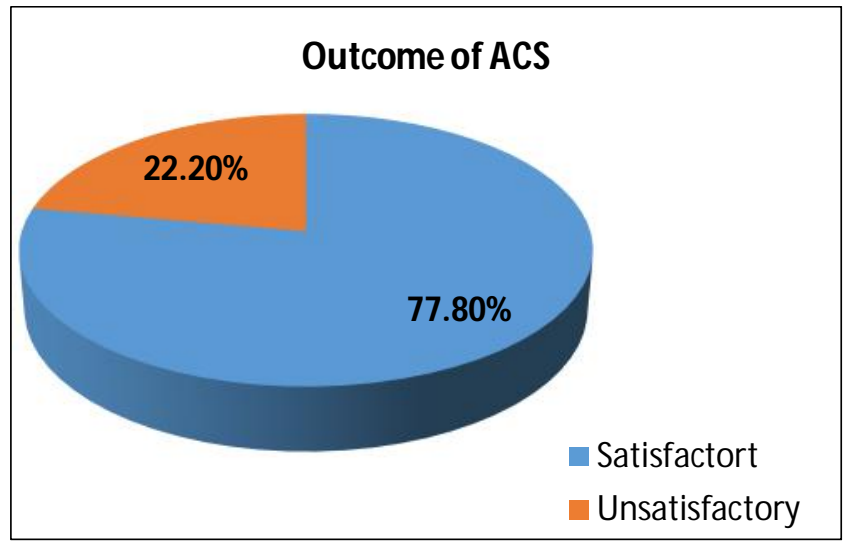

Figure-2: Distribution of ACS by clinical Outcome $(n=9)$

\section{Discussion}

This study encountered several limitations including lack of adequate documentation of all the relevant parameters for patients during their hospital stay. Total number of patients with limb injuries treated within the period was 320 . There was statistically significant $(p<0.05)$ male predominance among all trauma patients and male to female ratio was $5.1: 1$. The prevalence of ACS was $2.82 \%(n=9)$ with male to female ratio $3.5: 1,(p<0.05)$. About $44.4 \%$ patients were in age group of 20-29 years. Agu and Orjiaku found incidence of compartment syndrome was $1.02 \%$ despite the high number of limb injuries ${ }^{12}$. Some authors reported $2 \%{ }^{2,13}$. Road traffic accidents were main etiology in $55.56 \%$ cases; tibia fracture was the commonest (44.4\%), majority of which was closed fracture 33.3\%. However, Shore et al ${ }^{9}$ reported a high rate of $11.6 \%$ among teenagers who had tibia fractures. Some authors reported similar findings 3,4,8,9,12,14-19.

Sigamoney $\mathrm{K}$ et al15 evaluated that high energy injuries and polytrauma increase the risk of ACS. McQueen et al19 reported fractures were most often implicated in compartment syndrome, in as much as $69 \%$, as compared to $23.2 \%$ attributed to soft tissue injuries without fractures.Amongst fractures, most commonly observed were of the tibial diaphysis (36\%) and distal radius in $9.8 \%{ }^{19}$. In this study, the diagnoses were made using clinical methods only. When there was a clinical suspicion of ACS, the initial action would be to remove any external compressing materials such as bandages or splints and to elevate the leg to the level of the patient's heart. These were done for our patients with traditional bonesetters' splints. It is recommended that when in doubt, fasciotomy should be done, especially if the facilities for pressure measurement are not available. This is because the scar of fasciotomy wound is better than having contracture or losing a limb to gangrene ${ }^{17}$ due to late or misdiagnosis. It is also said that no one will blame the surgeon for carrying out fasciotomy, but everybody will blame the surgeon for missing the diagnosis of compartment syndrome ${ }^{12}$.

Compartment syndrome is more common in the leg than in the thigh or arm. However, a few numbers of cases in this study is not possible for a strong statistical inference. Two patients out of the 9 who presented to our center with traditional bonesetters' splint in place due to supracondylar fracture of humerus had compartment syndrome. Some reports have shown that tight traditional bonesetter's splint is a high-risk factor for developing gangrene from unrecognized progressive compartment syndrome that leads to amputation $6,17,18$. ACS complicates in closed tibia fractures more than in open fractures. Out of the nine patients five involved leg three of them were closed fracture tibia, one was Gustilo type II open tibia fracture due to gunshot injury. And another one blunt trauma leg without fracture due to physical assault. Common definitive treatment modality was open reduction and internal fixation (ORIF) with split thickness skin grafting (STSG) in one session (44.44\%) after fasciotomy. Fracture could be fixed at the same time of fasciotomy if the materials, especially the implants are available under such emergency condition and if the limb is judged to be viable. The pulse oximetry $\mathrm{SpO}_{2}$ and the state of the muscles as evidenced by contractility, color, bleeding, and texture are veritable guides to the viability of the tissue. Agu and Orjiaku followed the same treatment modalities ${ }^{12}$. We covered the fasciotomy wounds mostly by split thickness skin graft than by delayed primary or secondary suturing. Pyogenic osteomyelitis developed in $11.1 \%$ cases and in $77.8 \%$ cases no complication developed. Agu and Orjiaku found few fasciotomies wound infections, especially those that had prolonged healing without grafting. They were also the patients that had large scars' ${ }^{12}$. Perkins ZB et al16 observed $8.2 \%$ rate of amputation following CS.

Reamed intramedullary nailing increases the intraosseous pressure but this is usually not enough to cause a significant rise in compartment pressure ${ }^{19}$. Open reduction and plating is a good 
option. Three out of the four patients in this study with tibia fractures were treated initially by emergency fasciotomies and then delayed plating combined with skin grafting within the next 72 hours. External fixation also increases compartment pressure and also not to the level of clinical significance ${ }^{19}$. The range of hospital stay for the majority of the patients, especially those that had ORIF was 3 weeks (55.6\%). Patient treated by external fixations necessarily stayed longer in the hospital, 6-8 weeks. None of the patients in this study developed ischemic contracture on follow-ups. In this study, clinical outcome was evaluated at 6 months of surgery with pain score by Visual Analogue Scale and observing for complications to need further intervention. Satisfactory result was obtained in $77.8 \%$ cases. In the study of Lollo and Grabinsky ${ }^{20}, 14.7 \%$ of patients underwent further orthopedic surgery. At long-term follow-up, 10.2\% patients reported moderate lower extremity pain and $69.2 \%$ had returned to work. There were no associations observed between hours to fasciotomy, pain scores, opioid analgesic consumption rates, or return to work status at the 12-month clinic follow-up appointment.

\section{Conclusion}

Compartment syndrome is an orthopaedic emergency. An early high index of suspicion for this condition should be maintained when severe pain that is out of proportion to the injury specially in closed tibia fractures. Vigilant clinical assessment, close monitoring and prompt interventions are necessary to avoid disastrous neurologic and functional outcomes as well as to salvage the threatened limber life.

\section{References}

1. Pearse MF, Harry $L$ and NanchahalJ. ACS of the leg. BMJ 2002; 325:557-8.

2. Frink $M$, Hildebrand $F$, Krettek $C$ et al. Compartment syndrome of the lower leg and foot. Clin Orthop Relat Res 2010; 468:940-50.

3. McQueen MM, Christie J, Court-Brown CM. Acute compartment syndrome in tibialdiaphyseal fractures. J Bone Joint Surg Br 1996; 78:95-8.

4. Archbold HA, Wilson L, Barr RJ. Acute exertional compartment syndrome of the leg: Consequences of a delay in diagnosis: A report of 2 cases. Clin J Sport Med 2004; 14:98-100.

5. McQueen MM, Court-Brown CM. Compartment monitoring in tibial fractures. The pressure threshold for decompression. J Bone Joint Surg Br 1996; 78:99-104.

6. Agu TC, Onyekwelu J. Traditional bone setters' gangrene: An avoidable catastrophe, 8 years retrospective review in a private orthopaedic and trauma centre in Southeast Nigeria. Niger J Gen Pract 2016; 14:-5.
7. Mabvuure NT, Malahias M, Hindocha $S$ et al. Acute Compartment Syndrome of the Limbs: Current Concepts and Management. The Open Orthopaedics Journal 2012; 6:535-43.

8. Pearse MF, Harry L, Nanchahal J. Acute compartment syndrome of the leg. BMJ 2002; 325:557-8.

9. Shore BJ, Glotzbecker MP, Zurakowski D et al. Acute compartment syndrome in children and teenagers with tibia shaft fractures: Incidence and multivariable risk factors. J Orthop Trauma 2013; 27:616-21.

10. Ogunlusi JD, Oginni LM, Ikem IC. Normal leg compartment pressures in adult Nigerians using the Whitesides method. Iowa Orthop J 2005; 25:200-2.

11. Patel RV, Haddad FS. Compartment syndromes. Br J Hosp Med (Lond) 2005; 66:583-6.

12. Agu TC and Orjiaku ME. The prevalence and pattern of acute compartment syndrome of the limbs in a private orthopedic and trauma center, Southeast, Nigeria: 8 years retrospective study. Afr J Trauma 2016; 5:10-5.

13. Ganesan GR, Parachu KA, Syed FA et al. Forearm compartment syndrome following traditional bandage (putturkattu). Sch J Med Case Rep 2014; 2:325-7.

14. Wall CJ, Richardson MD, Lowe AJ et al. Survey of management of acute traumatic compartment syndrome of the leg in Australia.ANZ journal of Surgery 2007; 77(9):733-7.

15. Sigamoney $K$, Khincha $P$, Badge $R$ et al. Compartment syndrome: Challenges and solutions. Orthopedic Research and Reviews 2015; 7: 137-148.

16. Perkins $Z B$, Yet $B$, Glasgow $S$ et al. Meta-analysis of prognostic factors for amputation following surgical repair of lower extremity vascular trauma. Br J Surg 2015; 102:436-50.

17. Onuminya JE, Obekpa PO, Ihezue $\mathrm{HC}$ et al. Major amputations in Nigeria: A plea to educate traditional bone setters. Trop Doct 2000; 30:133-5.

18. Nwankwo OE, Katchy AU. Limb gangrene following treatment of limb injury by traditional bone setter (Tbs): A report of 15 consecutive cases. Niger Postgrad Med J 2005; 12:57-60.

19. McQueen MM, Christie J, Court-Brown CM. Compartment pressures after intramedullary nailing of the tibia. J Bone Joint Surg $\mathrm{Br}$ 1990; 72:395-7.

20. Lollo $L$ and Grabinsky A. Clinical and functional outcomes of acute lower extremity compartment syndrome at a Major Trauma Hospital. Int J CritlllnInj Sci 2016; 6(3):133-42. 